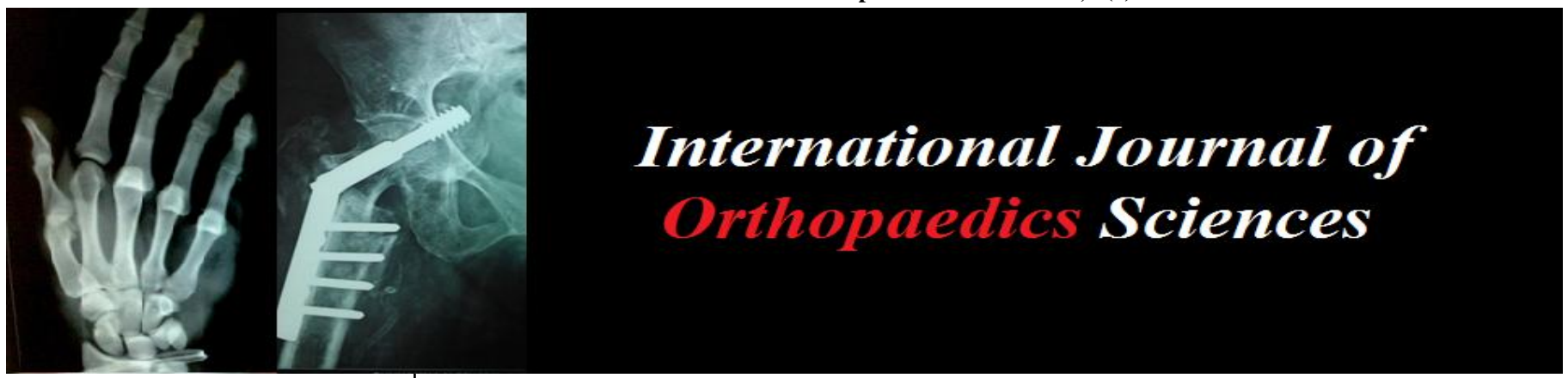

ISSN: $2395-1958$

IJOS 2017; 3(1): xx-xx

(C) 2017 IJOS

www.orthopaper.com

Received: 27-11-2016

Accepted: 28-12-2016

Dr. Bhavesh Jesalpura MS Orthopaedics SMS multispecialty hospital, Ahmedabad, Gujarat, India

Dr. Sharvil Gajjar

MS Ortho Chirayu hospital,

Ahmedabad, Gujarat, India
Correspondence

Dr. Sharvil Gajjar

MS Ortho Chirayu hospital,

Ahmedabad, Gujarat, India

\section{Primary prophylactic bone grafting for distal end radius fracture, Is it justified?}

\section{Dr. Bhavesh Jesalpura and Dr. Sharvil Gajjar}

DOI: $\underline{\text { http://dx.doi.org/10.22271/ortho.2017.v3.i1f.57 }}$

\section{Abstract}

Background: Our objective was to evaluate role of primary percutaneous bone grafting for extra articular fracture distal end radius and its usefulness in preventing secondary complications - collapse and stiffness.

Methods: 60 patients of extra articular fracture distal end radius were divided into two arms. All patients were treated with closed reduction and fixation in form of k-wires or external fixator or combination of both. Odd numbered patients (Group A) were treated with primary percutaneous bone grafting and even numbered patients (Group B) were treated with fixation without bone grafting. Patients were followed up to 1 year after fracture union with radiological and clinical evaluation based on modified Mayo wrist score.

Results: Irrespective of other factors, Radiological union was found to be faster by 12 days avg. in patients treated with primary percutaneous bone grafting. Modified Mayo wrist score also improved in patients treated with primary percutaneous bone grafting.

Conclusion: Though long term, multi centric, larger pool of patients based study is required to justify the use of primary percutaneous bone grafting in case of distal end radius extra articular fractures, in selected group of patients, it definitely helped to prevent secondary complications and improve functional outcome.

Keywords: fracture distal radius, extra articular, percutaneous bone grafting Osteoporosis

\section{Introduction}

$\mathrm{D} / \mathrm{E}$ radius is one of the commonest fractures ${ }^{[1-3]}$ since existence of mankind and it is having bimodal age distribution ${ }^{4}$ High energy fractures are comminuted, intra articular and associated with other trauma and requires CT scan for evaluation and treatment with a specific approach, whereas low energy fractures are mostly seen in elderly population, extra articular and usually osteoporotic fractures with less degree of displacement ${ }^{[5-9]}$.

Extra articular fractures are associated with a range of complications, like wrist stiffness, late collapse and arthritis of wrist joint and functional impairment. As the fractures involve the metaphyseal area of distal end of radius most of the fractures are associated with some degree of metaphyseal impaction and when reduced leave some void at fracture site. In elderly patients in addition to this metaphyseal void, there is poor bone healing due to osteoporosis ${ }^{[10-}$ ${ }^{15]}$. Based on this observation we decided to use primary percutaneous bone grafting (taken percutaneously from iliac crest under local anaesthesia with special bone graft retrieving trephine needle) for extraarticular fractures of D/E radius. And assess the usefulness of the same for prevention of secondary complications and improve functional outcome.

\section{Materials and Methods}

60 patients, who presented with extra articular fracture of distal end of radius, were enrolled under the program for evaluation between April 2014 to August 2014 at our institution, and were numbered from 1 to 60 . All patients underwent fixation with $\mathrm{K}$ wire, External Fixator or combination of both based on Severity of fracture and bone quality. Patients of Group A (i.e. Odd numbered patients) were treated with percutaneous bone graft taken from iliac crest under local anaesthesia in addition to fixation, whereas patients of Group B (Even numbered patients) were treated with only with Fixation. 
All the patients were called upon for weekly assessment for $1^{\text {st }}$ month, followed by biweekly assessment up to three months and then at 1 year. Radiographs were carried out at 1 month, 2 months and 3 months and 1 year. Clinical and functional assessments with Modified Mayo Score were carried out, once radiological signs of fracture union were visible and fixation was removed. Proper physiotherapy and supportive medicines were given to all the patients.

\subsection{Observation and results}

Statistical methods used: Chi Square test Out of 60 patients 41 were female and 17 were male. 2 patients were having bilateral fractures. Average Age was 57 years with range from 43 years to 71 years.

Average time for radiological union in Group A was 37 days (Range: 30 - 48 days) and in group B was 49 days (Range: 37 - 67 days), which is a significant difference.

Modified Mayo Wrist Score assessment was done and in Group A Average score (79; Range: 58-97), was better than average score in Group B (67; Range: 48-87).

\subsection{Case 1}

A 52 year old male patient was treated by closed reduction with $\mathrm{k}$ wiring and external fixator and percutaneous bone grafting. Post operatively patient had no collapse and good range of movements.

\subsection{Pre op}



Fig 1: Post op

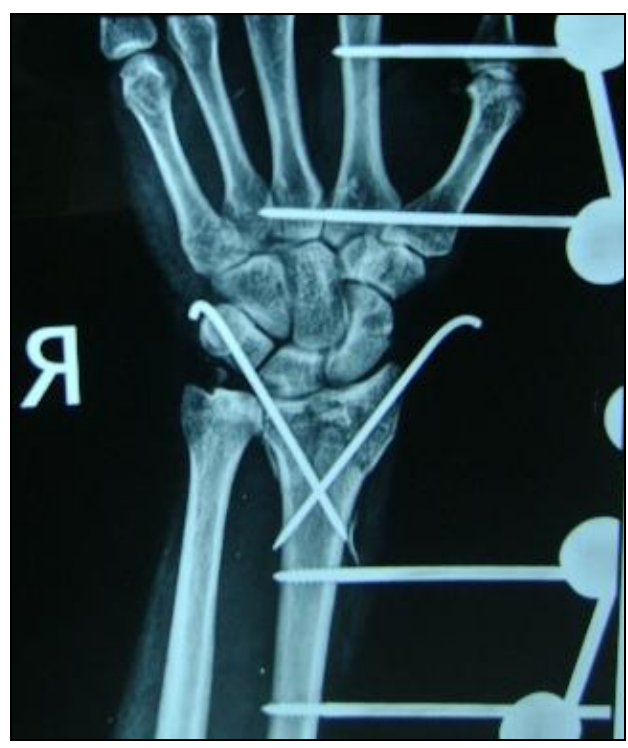

Fig 2

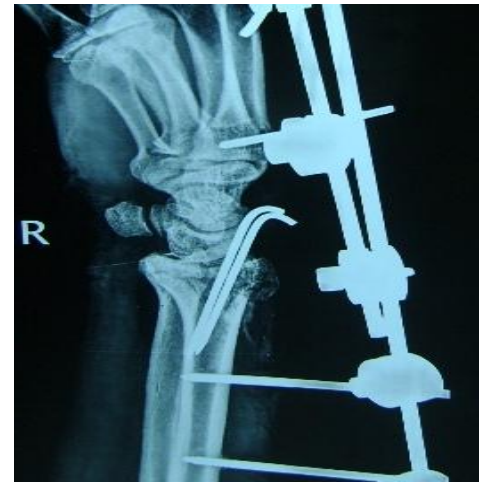

Fig 3: 6 month follow up:



Fig 4

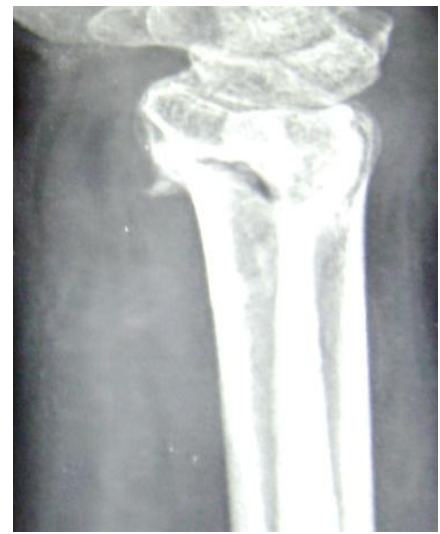

Fig 5

\subsection{Case 2}

A 40 year old male patient having RTA was treated with $\mathrm{k}$ wire but showed collapse at 3 months. Percutaneous bone grafting was not carried out in that patient suggestive of increased probability of collapse.

\subsection{Pre-op}

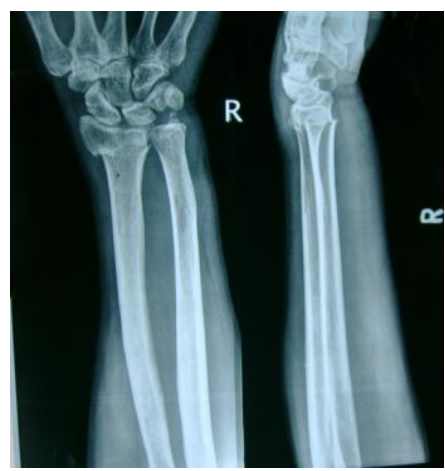

Fig 6: Immediate post-operative 


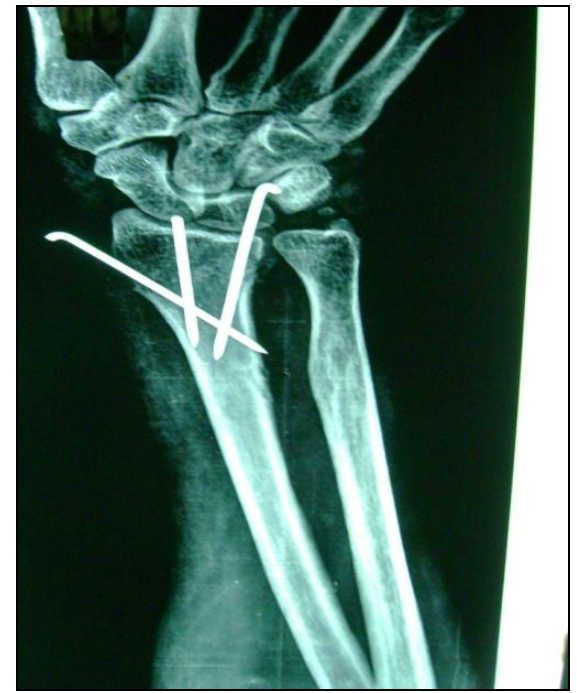

Fig 7

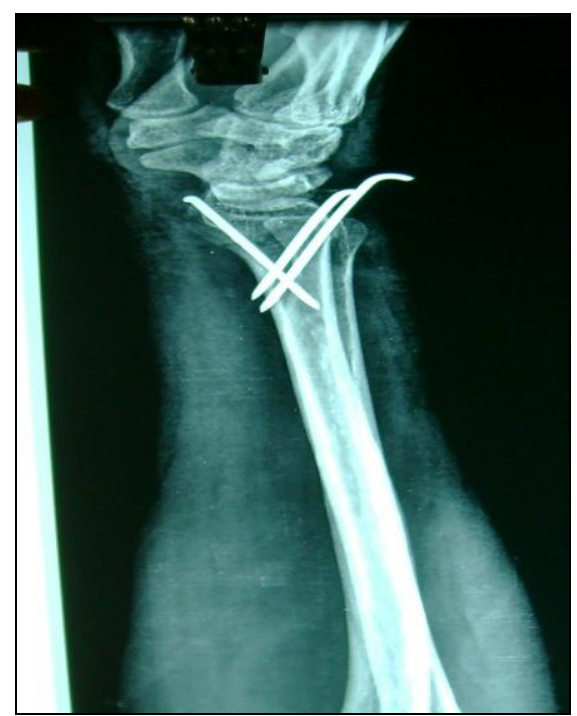

Fig 8: 3 months follow up

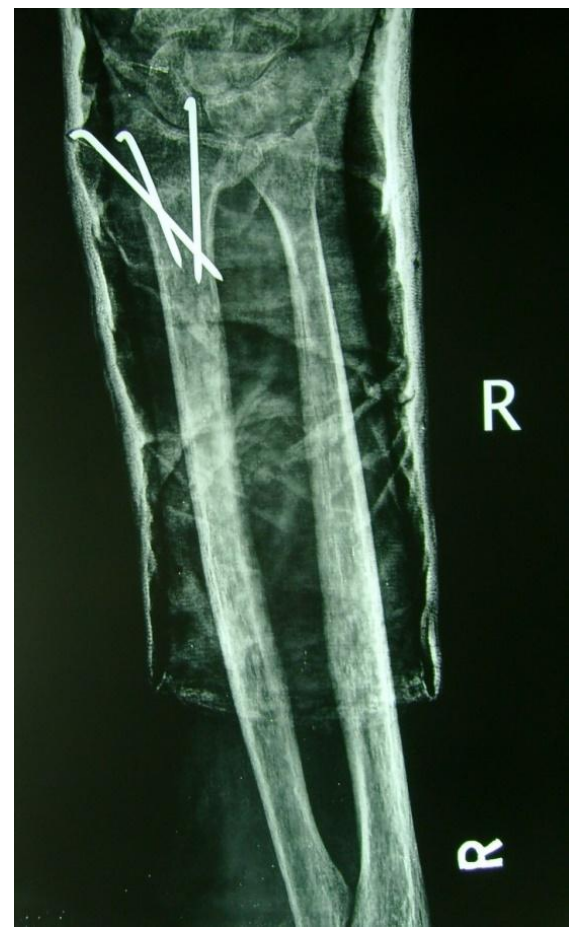

Fig 9

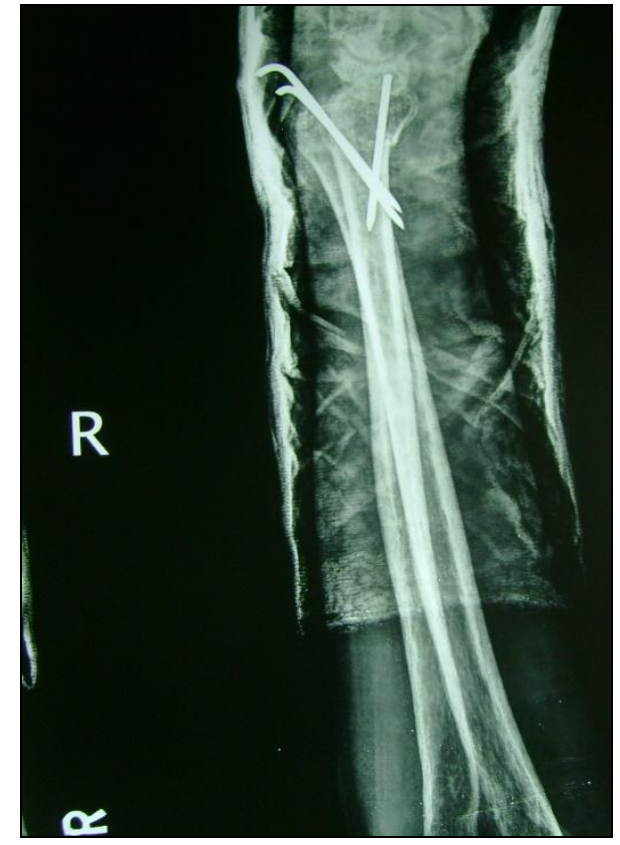

Fig 10

\section{Discussion}

As we can see from the results, women are affected as twice as men, because of more severity of osteoporosis in them and more chances of domestic fall in them. As these are low energy fractures, most of them can be treated with reduction under anaesthesia and K Wire or External fixator. As we have said, the rate of late collapse in distal end radius fracture due to metaphyseal void is one of the important factors in functional outcome. This metaphyseal void also leads to delay in healing and hence longer period of immobilization of wrist which leads to delayed physiotherapy and hence stiffness of wrist joint. As most of the patients of distal end radius fracture are of elderly age group their healing potential is poorer and some form of augmentation can be helpful in better healing of fracture. The main concern with Primary bone grafting is added morbidity and patient compliance. However due to percutaneous retrieval of bone graft under local anaesthesia, we have been able to convince patients without any problems. As introduced material at fracture site is having Osteogenic, Osteoinductive and Osteoconductive property and with very less additional cost, We have been able to achieve union at a faster rate and hence faster removal of external fixator or $\mathrm{K}$ wires and hence early rehabilitation and thereby prevention of secondary complications of stiffness and late collapse [16-19, 2628]

Modified Mayo Wrist Score is also better in patients with primary percutaneous bone grafting as compare to patients who have been treated with fixation. There was no infection at bone graft harvest site or introduction site. Some superficial Kwire and external fixator infection do occur, which resolve well once proper pin tract care taken during union and removal of implant ${ }^{[20-25]}$.

However our patient group size is very small, it is a retrospective study and was done at only one centre.

\section{Conclusion}

From above experience we conclude that, Primary percutaneous bone grafting in extra articular fracture distal end radius is definitely beneficial to the patient due to early union, faster rehabilitation and decrease in late collapse and stiffness. However further evaluation required with multicentric, prospective, randomised double blind studies. 


\section{References}

1. Golden GN Treatment and prognosis of Colles' fracture Lancet. 1963; 1(7280):511-515.

2. Hollingsworth R, Morris J. The importance of the ulnar side of the wrist in fractures of the distal end of the radius Injury. 1976; 7(4):263-266,

3. Owen RA, Melton LJ 3rd, Johnson KA. Incidence of Colles' fracture in a North American community. Am J Public Health. 1982; 72(6):605-607.

4. Alffram PA, Bauer GC. Epidemiology of fractures of the forearm. A biomechanical investigation of bone strength. J Bone Joint Surg Am. 1962; 44:105-114,

5. Gartland JJ, Jr, Werley CW. Evaluation of healed Colles' fractures. J Bone Joint Surg Am. 1951; 33(4):895-907,

6. Older TM, Stabler EV, Cassebaum WH. Colles fracture: evaluation and selection of therapy. J Trauma. 1965; 5:469-476,

7. Peltier LF Fractures of the distal end of the radius. An historical account. Clin Orthop Relat Res. 1984; 187:1822 ,

8. Andersen DJ, Blair WF, Steyers CM Jr. Classification of distal radius fractures: an analysis of interobserver reliability and intraobserver reproducibility. J Hand Surg Am. 1996; 21(4):574-582,

9. Kreder HJ, Hanel DP, McKee M. Consistency of AO fracture classification for the distal radius. J Bone Joint Surg Br. 1996; 78(5):726-731,

10. Van der Linden W, Ericson R. Colles' fracture. How should its displacement be measured and how should it be immobilized? J Bone Joint Surg Am. 1981; 63(8):12851288 ,

11. Pool C. Colles' fracture. A prospective study of treatment. J Bone Joint Surg Br. 1973; 55(3):540-544.

12. Solgaard S, Bunger C, Sllund K. Displaced distal radius fractures. A comparative study of early results following external fixation, functional bracing in supination, or dorsal plaster immobilization. Arch Orthop Trauma Surg. 1990; 109(1):34-38,

13. Collert S, Isacson J. Management of dislocated Colles' fractures. Clin Orthop Relat Res. 1978; 135:183-186.

14. McQueen MM, MacLaren A, Chalmers J. The value of remanipulating Colles' fractures. J Bone Joint Surg Br. 1986; 68(2):232-233,

15. Shin Ek, Jupiter Jb. Current Concepts in the Management of Distal Radius Fractures. Acta Chirurgiae Orthopaedicaeet Traumatologiae Čechosl. 2007; 74:233246

16. Fernandez DL, Wolfe SW. Distal Radius Fractures. In: Green DP, Hotchkiss RN, Pederson WC, Wolfe SW. (eds): Green's operative hand surg. Philadelphia, Elsevier Churchill Livingstone, 2005, 645-710.

17. Frykman GK. Fracture of the distal radius including sequelae: shoulder-hand-finger syndrome-disturbance in the distal radio ulnar joint and impairment of nerve function: A clinical andexperimental study. Acta orthop. scand. 1967; 108:1-155.

18. Harness NG, Meals RA. The history of fracture fixation of the hand and wrist. Clin. Orthop. 2006; 445:19-29.

19. Jupiter JB, Ring D, Weitzel PP. Surgical treatment of redisplaced fractures of the distal radius in patients older than60 years. J Hand Surg. Amer. 2002; 27:714-723.

20. Wolfe Sw, Swigart Cr, Grauer J, Slade Jf. 3rd, Panjabi MM. Augmented external fixation of distal radius fractures: a biomechanical analysis. J Hand Surg., 1998; 23-A:127-134,
21. Bower L. Translated by Tretter H, Luchini HB, Kreuz K, Russe OA, Bjornson RGB. The treatment of fractures. Translated from the13th German ed. New York, etc: Grune \& Stratton, 1956.

22. Cooney WP III, Linscheid RL, Dobyns JH. External pin fixation for unstable Colles' fractures. J Bone Joint Surg [Am]. 1979; 61-A:840-5.

23. Frykman G. Fracture of the distal radius including sequelae - shoulder hand- finger syndrome, disturbance in the distal radio-ulnar joint and impairment of nerve function: a clinical and experimental study. Acta Orthop Scand 1967, 108.

24. Green DP. Pins and plaster treatment of comminuted fractures of the distal end of the radius. J Bone Joint Surg [Am]. 1975; 57-A:304-10.

25. Jakob RP, Fernandez DL. The treatment of wrist fractures with the small AO external fixation device. In: Uhthoff $\mathrm{HK}$, ed. Currentconcepts of external fixation of fractures. Berlin etc.: Springer-Verlag, 1982, 307-14.

26. Kinninmonth A, Evans JH, Leung PC. A biomechanical study ofcomminuted distal radial fractures to assess the stabilising effectofprimary bonegrafting. The Hong KongOrthopaedic Association7th annual scientific congress, 1987.

27. Uhthoif HK, Rahn BA. Healing patterns of metaphyseal fractures. C/in Orthop 1981; 160:295-303.

28. Vidal J, Buscayret Ch, Paran M, Melka J. Liıamentotaxis. In: Mears DC, ed. External skeletal fixation. Baltimore, etc.: Williams \&Wilkins, 1983, 493-6. 